\title{
Erratum to: Impact of Obesity on Postoperative and Long-term Outcomes in a General Surgery Population: A Retrospective Cohort Study
}

Tabita M. Valentijn • Wael Galal • Sanne E. Hoeks • Yvette R. van Gestel · Hence J. Verhagen •

Robert J. Stolker

Published online: 23 August 2013

(c) Société Internationale de Chirurgie 2013

Erratum to: World J Surg 10.1007/s00268-013-2162-y

Tabita M. Valentijn and Wael Galal contributed equally to this work.

The online version of the original article can be found under doi:10.1007/s00268-013-2162-y.

T. M. Valentijn · W. Galal · S. E. Hoeks ·

Y. R. van Gestel · R. J. Stolker (ه)

Department of Anesthesiology, Erasmus University Medical Center, Room H-1273, P.O. Box 2040, 3000 CA Rotterdam, The

Netherlands

e-mail: r.stolker@erasmusmc.nl

T. M. Valentijn $\cdot$ W. Galal $\cdot$ H. J. Verhagen

Department of Vascular Surgery, Erasmus University Medical

Center, Rotterdam, The Netherlands

Y. R. van Gestel

Eindhoven Cancer Registry, Comprehensive Cancer Center

South (IKZ), Eindhoven, The Netherlands 